\title{
Solvation-Controlled Elastification and Shape- Recovery of Cellulose Nanocrystal-Based Aerogels
}

Dong Li, Yuhuan Wang, Fen Long, Lin Gan*, Jin Huang*

School of Chemistry and Chemical Engineering, and Chongqing Key Laboratory of Soft-Matter

Material Chemistry and Functional Manufacturing, Southwest University, 400715, Chongqing,

China.

Table S1. Nitrogen content ( $N \%$ ) of cellulose nanocrystal (CNC), carboxyl-grafted cellulose nanocrystal (CNC-COOH), and hydrazide-modified cellulose nanocrystal (CNC-NHNH${ }_{2}$; functionalization degree of hydrazide groups on the $\mathrm{CNC}-\mathrm{NHNH}_{2}$.

\begin{tabular}{cccc}
\hline Samples & CNC & CNC-COOH & CNC-NHNH $_{2}$ \\
\hline$N \%$ & 0.025 & 0.035 & 1.755 \\
$\begin{array}{c}\text { Hydrazide groups } \\
(\mathrm{mmol} / \mathrm{g})\end{array}$ & - & - & 25.44 \\
\hline
\end{tabular}

Table S2. Modification degree of aldehyde groups (-CHO \%) for aldehyde-terminated polyethylene glycol (OHC-PEG-CHO) with $\mathrm{PEG}_{4 \mathrm{k}}, \mathrm{PEG}_{6 \mathrm{k}}, \mathrm{PEG}_{8 \mathrm{k}}$, and $\mathrm{PEG}_{10 \mathrm{k}}$.

\begin{tabular}{cccc}
\hline Samples & $H_{\mathrm{a}}$ & $H_{\mathrm{f}}$ & $-\mathrm{CHO} \%$ \\
\hline PEG $_{4 \mathrm{k}}$ & 1.0 & 207.8 & 85.18 \\
PEG $_{6 \mathrm{k}}$ & 1.0 & 294.9 & 90.84 \\
PEG $_{8 \mathrm{k}}$ & 1.0 & 379.7 & 94.49 \\
PEG $_{10 \mathrm{k}}$ & 1.0 & 486.9 & 92.22 \\
\hline
\end{tabular}






Figure $\mathbf{S 1}{ }^{1} \mathrm{H}$ NMR spectrum of $\mathrm{CNC}, \mathrm{ADH}$, and $\mathrm{CNC}-\mathrm{NHNH}_{2}$ in $\mathrm{D}_{2} \mathrm{O}$.

a



C

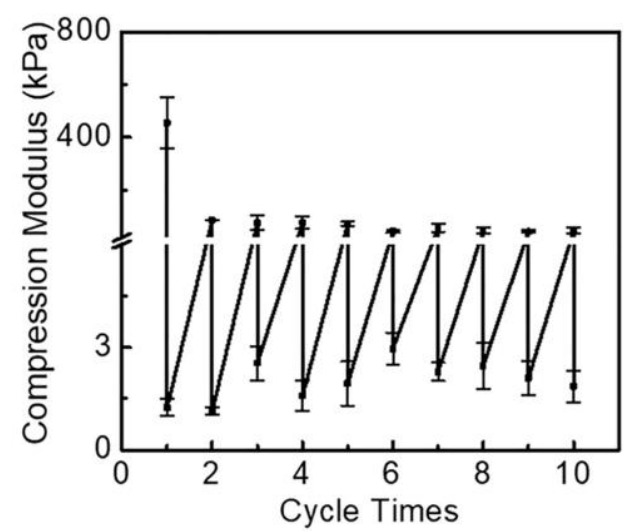

b

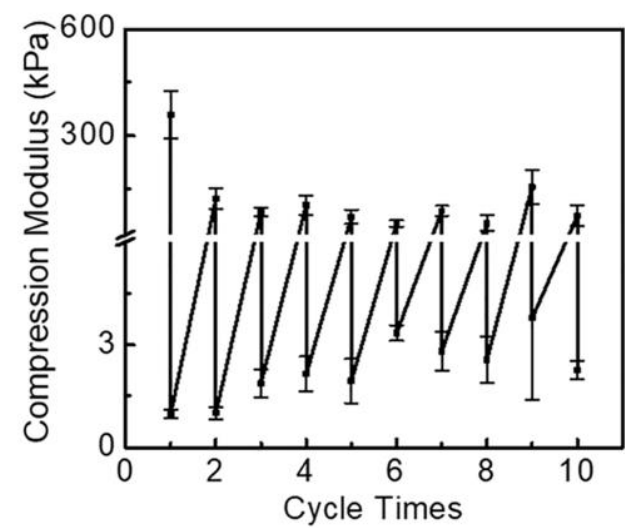

d

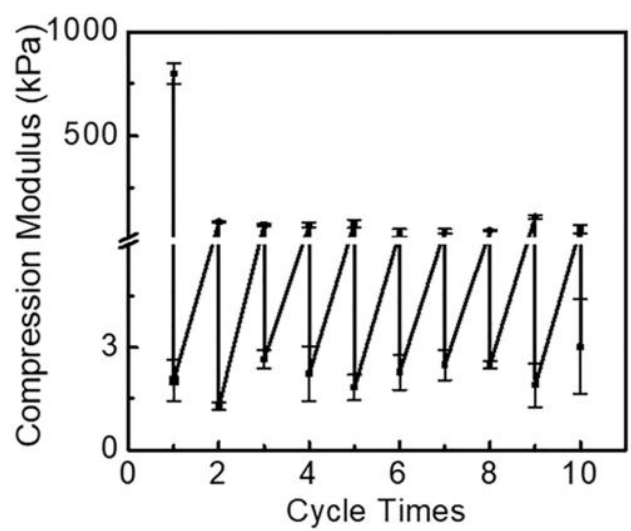

Figure S2. Cyclic compression modulus of (a) A-CNC-PEG 4 , (b) A-CNC-PEG 6 , (c) A-CNC$\mathrm{PEG}_{8 \mathrm{k}}$, and (d) A-CNC-PEG ${ }_{10 \mathrm{k}}$ in the dry state and in the water. 

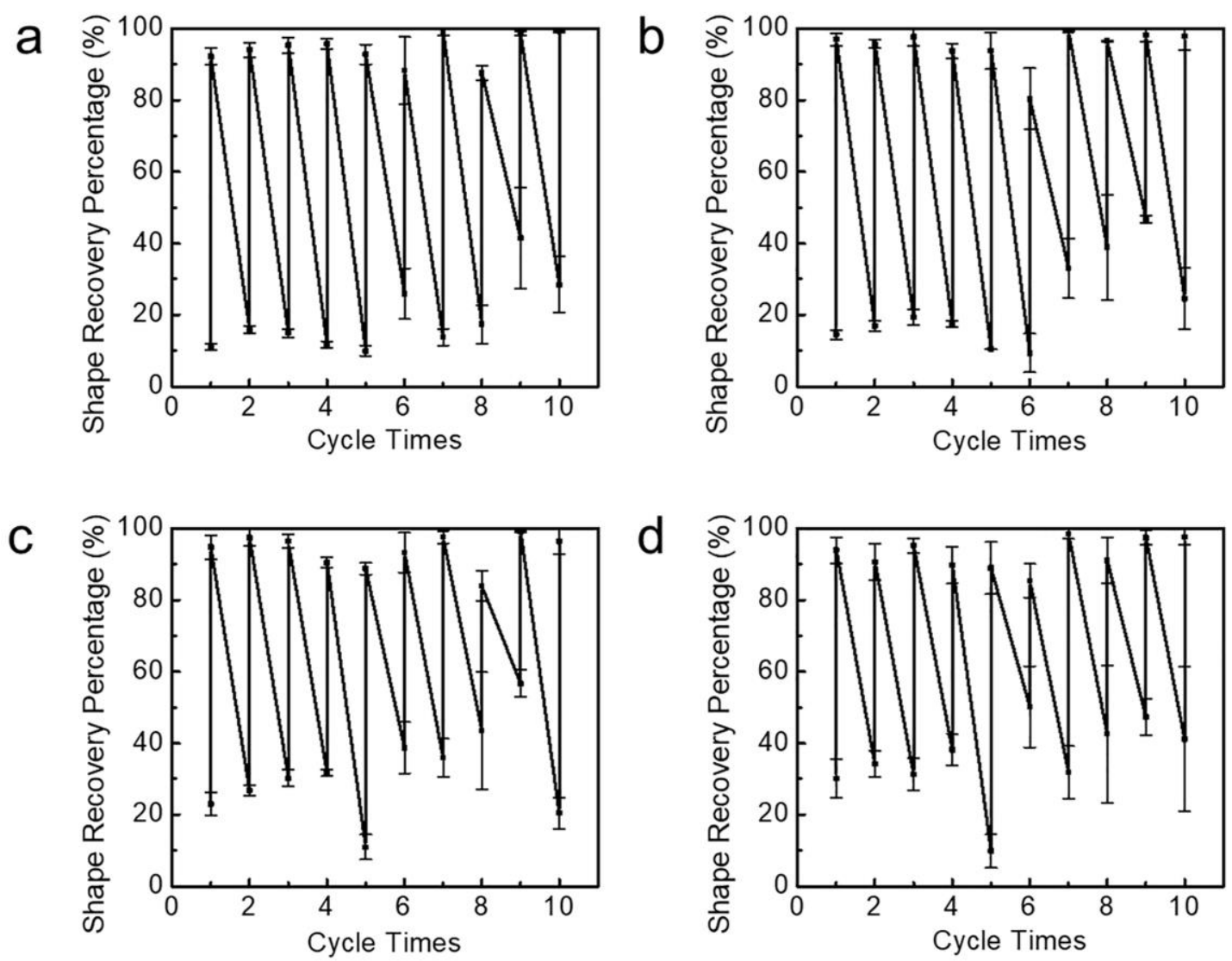

Figure S3. Cyclic shape recovery percentage of (a) A-CNC-PEG ${ }_{4 k}$, (b) A-CNC-PEG 6 , (c) A-

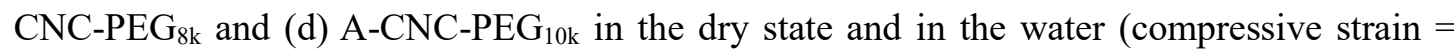
$50 \%)$.



Figure S4. Photographs of shape-recovery of A-CNC-PEG ${ }_{8 \mathrm{k}}$ in water, $N, N$-dimethylformamide 
$(\mathrm{DMF})$, ethanol, petroleum ether $(\mathrm{PE})($ compressive strain $=50 \%)$.

Since water could easily dissolve the PEG we used, we believed the material could be swelled instead of dissolved, indicating the material was crosslinked.
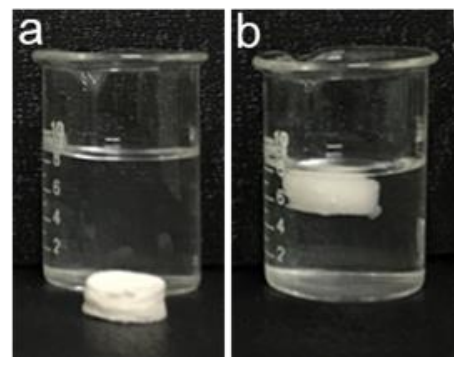

Figure S5. Photographs of shape-recovery of A-CNC-PEG ${ }_{8 \mathrm{k}}$ in acetone (compressive strain $=$ $50 \%)$.

Table S3. Intensity areas of compressive stress-strain curves for A-CNC-PEG 4 k, A-CNC$\mathrm{PEG}_{6 \mathrm{k}}, \mathrm{A}-\mathrm{CNC}-\mathrm{PEG}_{8 \mathrm{k}}$, and A-CNC-PEG $10 \mathrm{k}$ in the dry state and in the water.

\begin{tabular}{ccc}
\hline Samples & $\begin{array}{c}\text { Intensity ratios of compressive } \\
\text { stress-strain curves in the dry } \\
\text { state }(\mathrm{kPa})\end{array}$ & $\begin{array}{c}\text { Intensity ratios of compressive } \\
\text { stress-strain curves in the water } \\
(\mathrm{Pa})\end{array}$ \\
\hline A-CNC-PEG4k & 6.39 & 60.89 \\
A-CNC-PEG6k & 10.94 & 76.22 \\
A-CNC-PEG8k & 18.30 & 90.16 \\
A-CNC-PEG10k & 27.09 & 108.24 \\
\hline
\end{tabular}

Table S4. The melting enthalpy of non-compressed aerogel per gram $\left(\Delta H_{\mathrm{m}, \mathrm{n}}\right)$ and that of compressed aerogel $\left(\Delta H_{\mathrm{m}, \mathrm{c}}\right)$. The $T_{\mathrm{m}}$ range of non-compressed and compressed aerogel.

\begin{tabular}{lcc}
\hline \multirow{2}{*}{ Samples } & \multicolumn{2}{c}{$\mathrm{DSC}$} \\
\cline { 2 - 3 } & $T_{\mathrm{m}}$ range $\left({ }^{\circ} \mathrm{C}\right)$ & $\Delta H_{\mathrm{m}}(\mathrm{J} / \mathrm{g})$ \\
\hline A-4k non-compress & $40.7-53.3$ & 32.58 \\
A-4k compress & $41.0-51.9$ & 32.60 \\
A-6k non-compress & $41.3-55.6$ & 53.05 \\
A-6k compress & $41.5-54.7$ & 53.08 \\
A-8k non-compress & $47.7-58.8$ & 55.58 \\
A-8k compress & $47.3-57.7$ & 55.62 \\
A-10k non-compress & $49.8-60.8$ & 68.93 \\
A-10k compress & $49.7-60.7$ & 68.98 \\
\hline
\end{tabular}




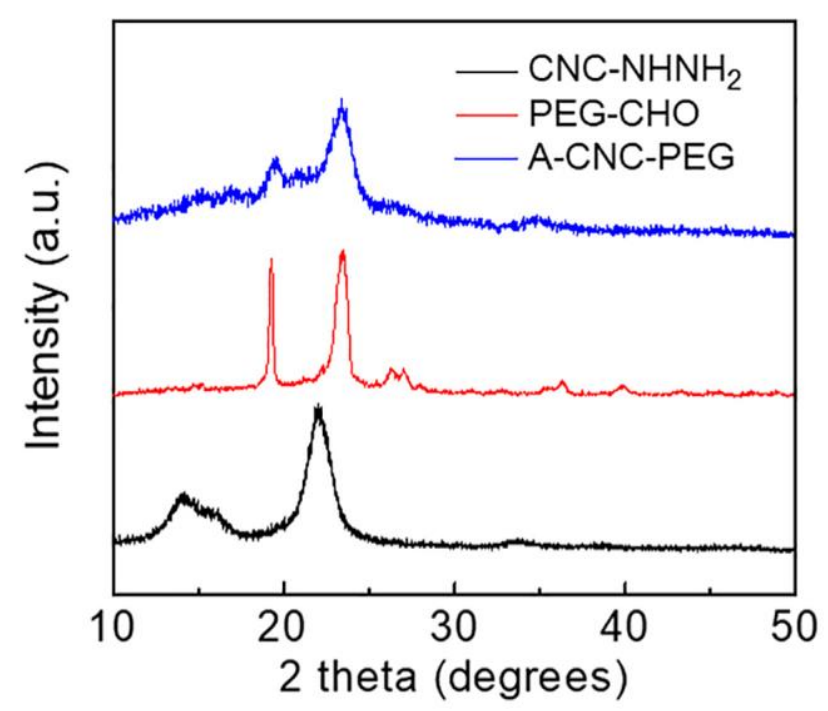

Figure S6. XRD of CNC-NHNH 2 , PEG-CHO and A-CNC-PEG.
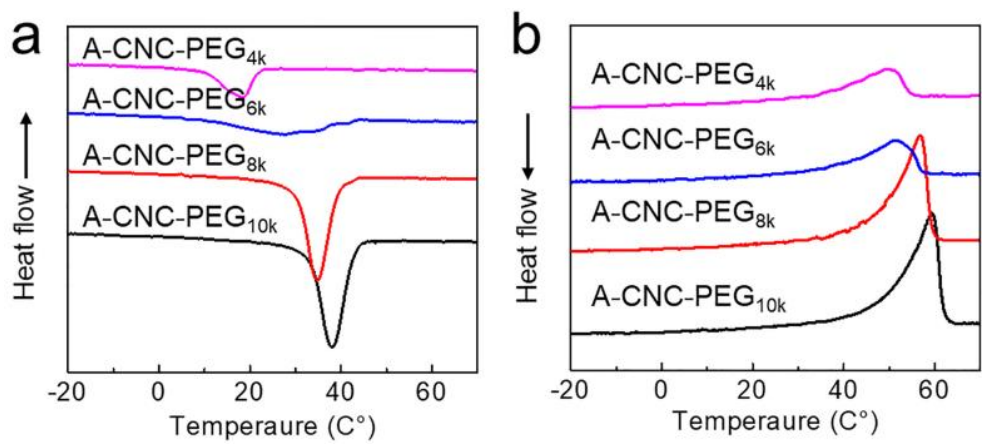

Figure S7. DSC of A-CNC-PEG phase change.

Table S5. Phase transition temperature and phase transition enthalpy of A-CNC-PEG.

\begin{tabular}{ccccc}
\hline \multirow{2}{*}{ Samples } & \multicolumn{4}{c}{$\mathrm{DSC}$} \\
\cline { 2 - 5 } & $T_{\mathrm{m} \text { range }\left({ }^{\circ} \mathrm{C}\right)}$ & $\Delta H_{\mathrm{m}}(\mathrm{J} / \mathrm{g})$ & $T_{\mathrm{c}}$ range $\left({ }^{\circ} \mathrm{C}\right)$ & $\Delta H_{\mathrm{c}}(\mathrm{J} / \mathrm{g})$ \\
\hline A-CNC-PEG $_{4 \mathrm{k}}$ & $39.9-54.4$ & 16.32 & $7.9-22.9$ & -14.56 \\
A-CNC-PEG $_{6 \mathrm{k}}$ & $36.3-57.9$ & 19.71 & $10.5-38.2$ & -13.65 \\
A-CNC-PEG $_{8 \mathrm{k}}$ & $44.5-60.8$ & 38.30 & $24.7-42.0$ & -42.21 \\
A-CNC-PEG $_{10 \mathrm{k}}$ & $44.2-63.7$ & 46.71 & $28.6-44.9$ & -47.57 \\
\hline
\end{tabular}


Table S6. The contact angle and surface energy of A-CNC-PEG 4 , A-CNC-PEG 6 k, A-CNC$\mathrm{PEG}_{8 \mathrm{k}}$ and A-CNC-PEG $10 \mathrm{k}$.

\begin{tabular}{|c|c|c|c|c|c|}
\hline \multirow{2}{*}{ Samples } & \multicolumn{2}{|c|}{ contact angle, $\theta$ (deg.) } & \multirow{2}{*}{$\gamma_{\mathrm{s}}^{\mathrm{d}}\left(\mathrm{mJ} / \mathrm{m}^{2}\right)^{\mathrm{a}}$} & \multirow{2}{*}{$\gamma_{\mathrm{s}}^{\mathrm{p}}\left(\mathrm{mJ} / \mathrm{m}^{2}\right)^{\mathrm{a}}$} & \multirow{2}{*}{$\gamma_{\mathrm{s}}\left(\mathrm{mJ} / \mathrm{m}^{2}\right)^{\mathrm{a}}$} \\
\hline & water & ethanol & & & \\
\hline $\mathrm{A}-\mathrm{CNC}-\mathrm{PEG}_{4 \mathrm{k}}$ & 46.6 & 38.5 & 4.4 & 52.3 & 56.7 \\
\hline A-CNC-PEG $6 \mathrm{k}$ & 51.3 & 40.8 & 5.7 & 45.2 & 50.9 \\
\hline $\mathrm{A}-\mathrm{CNC}-\mathrm{PEG}_{8 \mathrm{k}}$ & 55.6 & 41.3 & 8.2 & 37.3 & 45.5 \\
\hline A-CNC-PEG $10 \mathrm{k}$ & 72.3 & 51.5 & 15.5 & 16.6 & 32.1 \\
\hline
\end{tabular}

a To relate the dispersive and polar contributions of the surface energy using the Owens-Wendt approach, which were calculated according to the following equation:

$\gamma_{\mathrm{L}}(1+\cos \theta)=2 \sqrt{\gamma_{\mathrm{L}}^{\mathrm{d}} \gamma_{\mathrm{S}}^{\mathrm{d}}}+2 \sqrt{\gamma_{\mathrm{L}}^{\mathrm{p}} \gamma_{\mathrm{S}}^{\mathrm{p}}}$

where $\gamma, \gamma_{\mathrm{d}}$, and $\gamma_{\mathrm{p}}$ are the total, dispersive, and polar surface energies, respectively; $\theta$ is the contact angle; the subscripts of " $S$ " and " $\mathrm{L}$ " refer to the solid surface and the liquid drop, respectively; the $\gamma^{\mathrm{L}}, \gamma_{\mathrm{d}}^{\mathrm{L}}, \gamma_{\mathrm{p}}^{\mathrm{L}}$ values of water and ethanol are $72.8,21.8$, and $51.0 \mathrm{~mJ} / \mathrm{m}^{2}$, and 48.0, 29.0, and $19.0 \mathrm{~mJ} / \mathrm{m}^{2}$, respectively. ${ }^{1}$

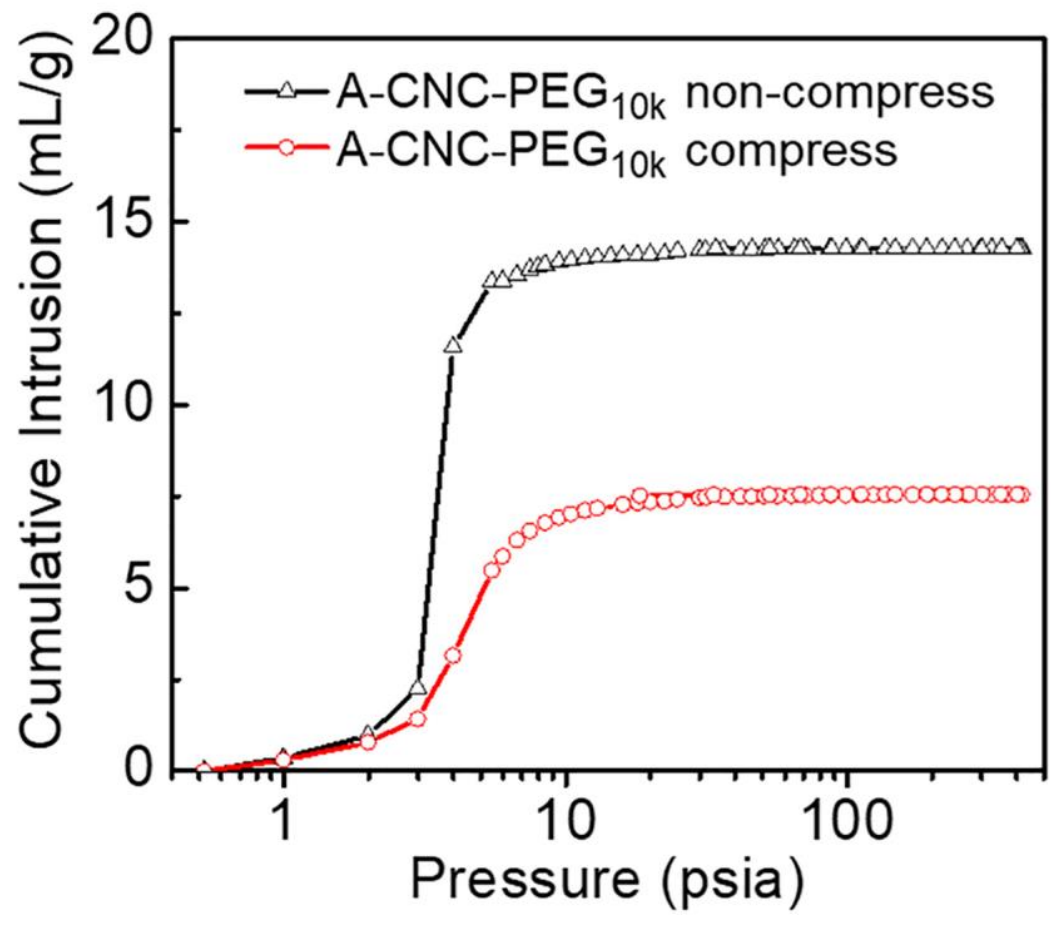


Figure S8. Curve of mercury injection and ejection for A-CNC-PEG ${ }_{10 \mathrm{k}}$ (the specific surface area of A-CNC-PEG non-compression was $1.244 \mathrm{~m}^{2} / \mathrm{g}$, and the specific surface area of A-CNCPEG compression was $0.951 \mathrm{~m}^{2} / \mathrm{g}$ )

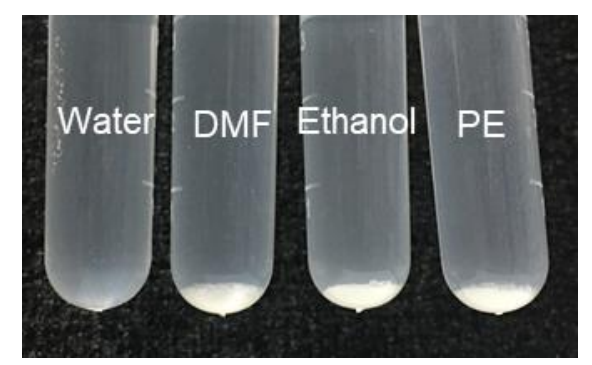

Figure S9. Photographs of $0.03 \mathrm{~g} \mathrm{PEG}_{6 \mathrm{k}}$ in $3 \mathrm{~mL}$ water, DMF, ethanol, and PE, respectively. By weighing the PEG precipitate and calculating, the solubility of $\mathrm{PEG}_{6 \mathrm{k}}$ in DMF, ethanol, and PE was $c a .0 .15,0.23$, and $0.13 \mathrm{wt} \%$, respectively.

\section{REFERENCES}

1. Gan, L.; Liao, J. L.; Lin, N.; Hu, C. L.; Wang, H. L.; Huang, J., Focus on Gradientwise Control of the Surface Acetylation of Cellulose Nanocrystals to Optimize Mechanical Reinforcement for Hydrophobic Polyester-Based Nanocomposites. ACS Omega 2017, 2, 4725-4736. 